\title{
Negros(as) intelectuais: descolonizando o saber e o poder
}

\author{
OLIVEIRA, Evaldo Ribeiro'
}

\section{RESUMO}

O presente trabalho busca discutir a importância dos intelectuais negros e negra para a construção de novas epistemologias, com o intuito de repensar o poder e a produção de conhecimento. Para tanto, se localiza dentro do contexto de lutas da população negra, não estamos falando de objetos de pesquisa, mas sim, de sujeitos produtores: de suas histórias; de suas pesquisas; suas epistemologias; seus lugares de fala. Desta forma, apresenta o contexto, demarcado pelas relações de poder, de colonialidade e descolonização. E apresentado uma breve compreensão do termo intelectual e por fim, aponta como "caminho": o "outro da razão", uma epistemologia desde o Sul, uma outra epistemologia, não hegemônica.

\section{Negros Intelectuais. Descolonização. Epistemologias}

\section{Intellectual Black People: decolonizing knowledge and power}

This work aims to discuss the importance of the intellectual black men and women to the construction of new epistemologies, in order to rethink the power and the knowledge production. Therefore, it"s placed inside the context of the black people movements, not by means of research objects, but subjects that build their own histories, their own researches, epistemologies and place of speech. In this way, it's presented the context, surrounded by power relations, of coloniality and decoloniality. Also, a brief comprehension of the intellectual concept and lastly, it's pointed as a "way": the "other side of the line", a south epistemology, and another, one that is not hegemonic.

Intellectual Black People. Decolonization. Epistemologies

\footnotetext{
${ }^{1}$ Professor Adjunto da Universidade da Integração Internacional da Lusofonia Afro-BrasileiraUNILAB (CE). Curso de Pedagogia e Bacharelado em Humanidades. Instituto de Humanidades (IH).e-mail: evaldo@unilab.edu.br
} 
Negros(as) intelectuais:

descolonizando o saber e o poder

\section{Negros(as) Intelectuais: poder, conhecimento e epistemologias}

No contexto brasileiro e mundial, vivemos em uma realidade na qual as lutas e bandeiras dos movimentos sociais são em parte alcançadas, porém, muito ainda necessita ser realizado, pois continua-se a negar a legitimidade das lutas e das conquistas dos marginalizados e oprimidos pela sociedade.

As tentativas de negação das conquistas dos marginalizados são realizadas, em inúmeras vezes, de forma silenciosa. Em muitas situações questiona-se o núcleo central dos grupos oprimidos e marginalizados, ou seja, aquilo que os fortalece enquanto grupos sociais, étnico-raciais específicos. Por exemplo, quando praticantes das religiões de matrizes africanas lutam contra a intolerância religiosa, contra os questionamentos se as práticas realizadas são religiosas. Ao questionarem, se as mesmas podem ser intituladas de religião africana ou afro-africana, questiona-se se os negros(as) têm religiões específicas.

Outro exemplo de tentativa de negação das especificidades do povo negro se observa quando, ao lutarem e buscarem ingressar no ensino superior por meio de ações afirmativas, os mesmos serem questionados, ao concluírem o ensino fundamental e médio, para quê querem ter formação superior, se não deveriam buscar o ensino profissionalizante. Ao insistirem, os/as negros/as, por ações afirmativas no ensino superior, questiona-se se tal iniciativa não provocaria o racismo, ou menosprezo aos negros, se não se deveria investir na educação básica, já que todos são iguais perante a lei, e que, por isso, não há racismo e nem discriminação no campo educacional.

Diante do quadro acima exposto, este trabalho se localiza dentro do contexto de lutas dos oprimidos, notadamente do povo negro. Ao realizar tão complexa tarefa, temos presente Fiori $(1970$, p. 12) quando afirma que "[...] os caminhos da libertação são os do oprimido que se libera: ele não é coisa que se resgata, é sujeito que se deve autoconfigurar responsavelmente". Assim, pois, não será inoportuno lembrar que, quando tratamos de negros e negras nesta produção não estamos falando de objetos de pesquisa, mas sim, de sujeitos produtores: de suas histórias; de suas pesquisas; suas epistemologias; seus lugares de fala.

A sociedade ocidental construiu e constrói a cultura e a crença de que os negros/as não são dotados de capacidades intelectuais, não são aptos a criar, pensar, filosofar, produzir ciências, entre outras formas de expressar conhecimentos, criatividade. São, negros e negras, julgados, e porque não dizer condenados a serem representados apenas como força física, bruta, irracional, sem cultura, semovente, enfim, sem humanidade. (MAZRUI, 2010). 695):

Nesse sentido, cabe atentar para as considerações de Mazrui (2010, p. 
Negros(as) intelectuais:

descolonizando o saber e o poder

O ocidente conheceu um movimento intelectual que não facultava aos africanos nenhuma capacidade artística [...]

$\mathrm{Na}$ América do Norte, Thomas Jefferson negou aos negros a atribuição de qualquer capacidade em matéria de arte ou poesia. Em suas Notes on the State of Virginia [Notas sobre o Estado da Virginia, Paris, 1784], ele procede a seguinte singular observação:

"Eu ainda não pude constatar que um homem negro tenha expresso um pensamento além do simples âmbito da narração; tampouco pude observar qualquer indício elementar de pintura ou de escultura. No tocante a música eles apresentam, em geral, maior capacidade que os brancos, dispondo de um ouvido muito afiado em relação aos acordes e ao ritmo, eles demonstram-se, inclusive, aptos a conceber um pequeno cânone. Entretanto, a sua aptidão em compor uma melodia mais extensa ou uma harmonia de maior complexidade, permanece a demonstrar".

Essa forma de pensamento, descrita por Mazrui (2010), tem impregnado corpos e mentes até os dias atuais e influenciado diversas gerações. Mais do que isso, valendo-se de diversos meios para propagar tais pensamentos, destrói-se qualquer forma de questionamento, de reconhecer novas possibilidades de interpretações sociais, étnico-raciais e culturais.

Exemplo disso é o artigo publicado, no início de dezembro de 2011, no jornal Folha de São Paulo, escrito pelo reconhecido poeta Ferreira Gullar, detentor de Prêmio Jabuti (2011), considerado por alguns especialistas da área como o maior poeta brasileiro vivo. No mencionado artigo, intitulado Preconceito cultural, o poeta debate a respeito da existência ou não de uma literatura negra, defendendo a não existência. O debate é salutar, não é esta a questão, mas sim, a negação de especificidades de literatura produzida a partir da experiência de ser negro, de ser negra. Diz Ferreira Gullar (2011):

Falar de literatura brasileira negra não tem cabimento. Os negros, que para cá vieram na condição de escravos, não tinham literatura, já que essa manifestação não fazia parte de sua cultura. Consequentemente, foi aqui que tomaram conhecimento dela e, com os anos, passaram a cultivá-la. (GULLAR, 2011, grifo nosso).

O poeta deixa bem explícito a concepção de negro que está presente na sociedade brasileira, o lugar que a sociedade destina aos negros. $\mathrm{O}$ apreciado e reconhecido poeta prossegue:

A contribuição do negro à cultura brasileira é inestimável, a tal ponto que falar de contribuição é pouco, uma vez que ela é constitutiva dessa cultura.

O Brasil não seria o país que o mundo conhece - e que nós amamos - sem a música que tem, sem a dança que tem, criada em grande parte pelos negros.

Ninguém hoje pode imaginar este país sem os desfiles de escolas de samba, sem a dança de suas passistas, o ritmo de 
Negros(as) intelectuais:

sua bateria, a beleza e euforia que fascinam o mundo inteiro. (GULLAR, 2011, grifo nosso).

O poeta demonstra empáfia e/ou não reconhecimento da riqueza da produção literária dos(as) negros(as), não só nas culturas africanas, como também nas dos povos originários do Brasil. Mais do que isso, ele ignora a produção de poetas e poetizas negras ao longo do século XX. Autores de poemas, cuja referência são experiências do dia a dia vividas por pessoas negras. Vejam-se, por exemplo, as obras de Luiz Gama, Cruz e Souza, e mais recentemente, Cuti, Esmeralda Ribeiro, Jônatas Conceição, Márcio Barbosa, Miriam Alves, Oliveira Silveira, entre tantos outros.

Em algumas sociedades, dentre elas, a brasileira, muitas pessoas e instituições públicas e privadas buscam se constituir, entre outras coisas, a partir da ideia do mérito, no sentido de capacidade individual. Estas pessoas e instituições partem do princípio da meritocracia, que é assim definida por Lorenzo Fischer (1998, p. 747):

Em geral, por meritocracia se entende o poder da inteligência que, nas sociedades industriais, estaria substituindo o poder baseado no nascimento ou na riqueza, em virtude da função exercida pela escola. De acordo com esta definição, os méritos dos indivíduos, decorrentes principalmente das aptidões intelectivas que são confirmadas no sistema escolar mediante diplomas e títulos, viriam a constituir a base indispensável.

No mesmo sentido, Lima (1996, p. 201) destaca que a meritocracia:

Tem sido um valor criado e reproduzido nas diversas formações sociais e, enquanto parte integrante de processos ideológicos de dominação, é elevado à categoria de verdadeiro em si próprio. É como se o talento para o sucesso dependesse única e exclusivamente do indivíduo, sem qualquer interferência do meio [...] mérito não significa outra coisa que a competência específica para determinada ação ou posição, de acordo com os parâmetros preestabelecidos por algo ou alguém.

Assim, a meritocracia, entre outros fatores, provoca estereótipos, e consequentemente, leva a formulação de julgamentos, preconceitos como teria acontecido com o do Ferreira Gullar, que não concebe que os negros sejam produtores de uma literatura que possa ser qualificada e identificada como negra. Mais do que isso, tal pensamento busca afirmar o:

lugar do negro que o branco racista determinou, um lugar que serviu de 'contribuição' para que os brancos ganhassem dinheiro, não só produzindo sua arte a partir do aprendizado com os negros, mas também explorando compositores diretamente e calando-os na sua autoafirmação étnica. (CUTI, 2011). 
Negros(as) intelectuais:

Cuti (2011), em crítica as expressões de Gullar, diz que, os "[...] pobres argumentos está a ruminar que a literatura não pode ser negra. Talvez sinta que a negrura pode sujá-la, postura bem ainda dentro do diapasão modernista que abordou o negro pelo viés da folclorização".

Para romper com esse pensamento, expresso por Ferreira Gullar, é necessário descolonizar o poder e o saber que se querem dominantes.

"Poder", neste trabalho, é entendido como "[...] perspectiva cognitiva producida en el largo tiempo del conjunto del mundo eurocentrado del capitalismo colonial/moderno y que naturaliza la experiencia de las gentes en este patrón de poder" (QUIJANO, 2000a, p. 287) que são percibidas como "[...] naturales, en consecuencia como dados, no susceptibles de ser cuestionados". (Ibidem, p. 343). Mais do que isso, continua Quijano (Ibidem, p. 289), o poder é:

[...] un espacio y una malla de relaciones sociales de explotación/dominación/ conflicto articuladas, básicamente, en función y en torno de la disputa por el control de los siguientes ámbitos de existencia social: (1) el trabajo y sus productos; (2) en dependencia del anterior, la "naturaleza" y sus recursos de producción; (3) el sexo, sus productos y la reproducción de la especie; (4) la subjetividad y sus productos, materiales e intersubjetivos, incluído el conocimiento; (5) la autoridad y sus instrumentos, de coerción en particular, para asegurar la reproducción de ese patrón de relaciones sociales y regular sus cambios.

Ao se referir à "descolonialidade do poder" é importante compreender a colonialidade como um dos dados constitutivos das esferas de poder, que se ancora na imposição sobre um grupo étnico-racial, sendo que, neste caso, brancos descendentes de europeus sobre outros, no presente caso, dos negros descendentes de africanos, e "[...] opera en cada uno de los planos, ámbitos y dimensiones, materiales y subjetivas de la existencia cotidiana y escala social”. (Ibidem, p. 285).

No entendimento de Quijano (Ibidem, p. 287), a colonialidade "[...] parte de una concepción de humanidad según la cual la población del mundo se diferenciaba en inferiores y superiores, irracionales y racionales, primitivos y civilizados, tradicionales y modernos".

Cabe destacar que, a colonialidade está vinculada ao colonialismo, que se refere a uma estrutura de dominação e exploração política, cultural e racial no campo dos "[...] recursos de producción y del trabajo de una población determinada lo detenta otra de diferente identidad [...]". (Ibidem, p. 286).

A colonialidade do poder "[...] ejerce su dominio, [...] en contra de la democracia, la ciudadanía, la nación y el Estado-nación moderno" (QUIJANO, 2000b, p.237), e por que não dizer que a colonialidade também busca exercer 
Negros(as) intelectuais:

o poder sobre as ciências, as culturas, as religiões, entre outros campos de organização e de expressão humana.

Assim sendo, descolonizar o poder implica romper com a lógica que cria relações entre dominadores e dominados, opressores e oprimidos, brancos e negros, homens e mulheres, centro e periferia, entre outros meios de conexão entre pessoas, grupos, sociedades. Segundo Quijano (2007, p. 4):

[...] nuestra emancipación del Eurocentrismo, esa forma de producir subjetividad (imaginario social, memoria histórica y conocimiento) de modo distorsionado y distorsionante, que, aparte de la violencia, es el más eficaz instrumento de control que el capitalismo colonial/moderno tiene para mantener la existencia social de la especie humana dentro de este patrón de poder.

Descolonizar o saber se faz necessário nas sociedades onde "[...] la colonización implicó la destrucción de la estructura societal, la población colonizada fue despojada de sus saberes intelectuales y de sus medios de expresión exteriorizantes $u$ objetivantes. Fueron reducidos a la condiciòn de gentes rurales e iletradas". (Idem, 2000a, p. 378).

No campo teórico desta pesquisa, como de outras que buscam conhecer a perspectiva dos colonizados, dos oprimidos, um dos grandes desafios está em romper com a colonialidade do saber. Conforme destaca Edgardo Lander (2000, p. 11):

la búsqueda de alternativas a la conformación profundamente excluyente y desigual del mundo moderno exige un esfuerzo de deconstrucción del carácter universal y natural de la sociedad capitalista-liberal. Esto requiere el cuestionamiento de las pretensiones de objetividad y neutralidad de los principales instrumentos de naturalización y legitimación de este orden social: el conjunto de saberes que conocemos globalmente como ciencias sociales.

Buscar alternativas na literatura para a compreensão de quem seja e quais as perceptivas de negros reconhecidos como intelectuais, faz-se urgente, pois outras compreensões, para além daquelas construídas em contextos coloniais, são necessárias, para pensar novas epistemologias.

Intelectual: Breves Compreensões

"Intelectual" é uma palavra forjada no universo ocidental, com essa afirmação, quero sublinhar que, ao buscar significados para "intelectual" que estão forjados em contextos não eurocêntricos, a intenção é buscar valores culturais, sociais, políticos, religiosos que a palavra "intelectual" e outras correspondentes podem encerrar. 
Negros(as) intelectuais:

Dizer quem são os intelectuais não é uma tarefa fácil, pois, como salientou Sartre (1994, p. 32), um intelectual se "[...] caracteriza por não ter mandato de ninguém e por não ter recebido seu estado de nenhuma autoridade".

Cabe salientar que, o objetivo deste capítulo não é buscar um entendimento único e assertivo do termo, conforme questiona Gramsci (1982, p. 6), ao perguntar '[...] quais são os limites 'máximos' da acepção de 'intelectual"? É possível, indaga o autor citado, "encontrar um critério unitário para caracterizar igualmente todas as diversas e variadas atividades intelectuais e para distingui-las, ao mesmo tempo e de modo essencial, dos outros agrupamentos sociais?" (Ibidem, p. 6).

Os estudos que tratam sobre intelectuais são muitos, assim como os significados atribuídos nas múltiplas "definições para o termo intelectual" (SOUZA, D. 2009, p. 55), que vem sendo construídas desde a criação do termo, nos primeiros anos do século XIX.

Ao buscar compreender os significados presentes na literatura sobre quem são os intelectuais, é importante demarcar que há diferenças nas concepções e compreensões, que são de cunho ideológico, cultural, social e étnico-racial, além das circunstâncias temporais, históricas em que foram formuladas. Como toda produção humana, as compreensões do termo "intelectual" são passíveis de críticas e questionamentos. Cabe destacar que ao apresentá-las, não significa que sejam necessariamente adotadas nesta pesquisa, mas que é fundamental apresentar os significados presentes no campo de estudo. De acordo com Bauman (2010, p. 15),

Quando foi cunhada, nos primeiros anos do século $X X$, a palavra "intelectual" era uma tentativa de recapturar e reafirmar a centralidade social e as preocupações globais que estiveram associadas à produção e disseminação do conhecimento durante o lluminismo. Ela era aplicada a uma série heterogênea de romancistas, poetas, artistas, jornalistas, cientistas e outras figuras públicas que sentiam coletivo, interferir de modo direto no processo político por meio da influência que exerceriam sobre as mentalidades da nação e moldar as ações de seus líderes políticos.

$\mathrm{Na}$ época em que a palavra foi criada, os descendentes dos 'philosophes' ou da 'République des Lettres' já tinham se dividido em enclaves especializados, com seus interesses parciais e preocupações localizadas. A palavra, por conseguinte, foi um toque de reunir, tangido por sobre as bemguardadas fronteiras das profissões e dos gêneros artísticos; um chamado para ressuscitar a tradição (ou materializar a memória coletiva) de "homens de conhecimento", e para encarnar e praticar a unidade da verdade, dos valores morais e dos juízos estéticos. 
Negros(as) intelectuais:

Ciente que este artigo discutir a importância dos intelectuais negros e negra para a construção de novas epistemologias, cabe retomar as ideias de Santos (2004, p. 77), que disse que o intelectual é

como a champagne, a bautecoutre, a baquette, é uma invenção francesa. Em cidades da África do Norte se veem nas ruas sujeitos em banquinhos escrevendo. Não escrevem nada seu, são escreventes públicos, apenas dão forma a ideias que outros pensaram mais e melhor que eles. Eis aí uma outra definição de intelectual: porta-voz de um grupo, de uma classe. Os escreventes públicos africanos se dão ares de importância, olham e pousam a caneta como sábios indiferentes aos mortais que lhes pagam para formatar ideias e sentimentos.

Nessa direção, cabe chamar a atenção para o entendimento que designa, em muitos casos, pessoas como intelectuais em função de sua profissão. Desta forma, é comum se identificar como intelectuais as pessoas que têm avançada formação acadêmica ou produção artística avaliada como valorosa.

A respeito disso, Vieira (2008, p. 71) pondera que, as palavras como "sábio", "erudito", "letrado" e "culto" representam adjetivos associados a sujeitos privados e a experiências privadas, enquanto "intelectual/intelectuais", criadas no século XIX, na Europa, designa protagonismo político exercido por aqueles que, em séculos anteriores, eram designados como sábios. Para o autor, no contexto francês, no qual foi criado o termo "intelectual", por um lado "[...] os intelectuais foram compreendidos como defensores intransigentes da liberdade e da justiça e, por outro lado, como traidores da pátria e da nação". (Ibidem, p. 71). Já no contexto russo, o termo correspondente a intelectual, intelligentsia, "sugeria o empenho político dos jovens literatos contra o csarismo". (Ibidem, p. 71).

Cabe destacar que, o uso do termo, no século XIX, reforça a ideia que vinha sendo gerada desde Cícero no Império Romano até Voltaire na França pré-revolucionária, na qual já "[...] prenunciavam esse encontro entre sábios e esfera pública. Em outros termos, a intervenção dos cultos na cena pública não é uma inovação do século XIX" (VIEIRA, 2008, p. 71-72), entretanto, havia "[...] condições materiais de organização da cultura nesse período, particularmente favorecida pela presença de jornais e de revistas de ampla circulação, propiciaram a formação da identidade dos intelectuais como protagonistas políticos". (Ibidem, p. 71-72).

Foi o protagonismo político que criou, divulgou e tornou corrente o uso da palavra "intelectual" no século XIX, na França, e a partir das ações de um grupo de debates em torno do caso Dreyfrus. (VIEIRA, 2008; SILVA, 2005; OUTHWAITE; BOTTOMORRE, 1996; ZUIM, 2003). Caso assim explicado: "[...] o capitão Alfred Dreyfus foi acusado de traição pelas forças armadas francesas por atos de espionagem em favor da Alemanha" (SILVA, 2003, p. 01), sendo 
que, conscientes das divergências e erros no julgamento, um grupo de escritores, artistas, políticos, publicaram o "manifesto dos intelectuais", solicitando a revisão do processo do capitão Dreyfus. Segundo Vieira (2008, p. 71, grifo nosso), "o episódio demarcou a ação pública de artistas, cientistas e escritores contra o Estado pela quebra de normas jurídicas no processo que este movia contra o capitão Alfred Dreyfus, acusado em 1894 de espionagem em favor da Alemanha".

$\mathrm{Na}$ construção dos significados do termo "intelectual", é importante destacar que, foi por meio de ação de pessoas, os defensores do caso Dreyfrus, que o termo enquanto tal foi constituído, ou seja, a palavra nasceu por meio de ações de um grupo de pessoas conscientes dos equívocos de um julgamento, embora, conforme dito anteriormente, o [...] termo circulasse amplamente no ambiente cultural francês da segunda metade do século XIX. O marco simbólico da sua emergência foi o já célebre manifesto "J'accuse: lettre au président de la république", de Émile Zola, publicado no jornal L'Aurore, em dezembro de 1898. (Ibidem, p. 70). É importante atentarmos para as palavras de Bobbio (1998, p. 647), que assim diz: [...] "recebido com desconfiança nos dicionários e considerado frequentemente como gíria ou expressão depreciativa, o termo intelectuais conserva ainda o sentido político que recebeu como se fosse um nome de guerra".

O termo intelectual, para Bobbio (1998, p. 637), está relacionado a uma "[...] categoria ou classe social particular, que se distingue pela instrução e pela competência, científica, técnica ou administrativa".

Segundo Gramsci (1979, p. 5), cada sociedade "[...] encontrou, pelo menos na história que se desenrolou até aos nossos dias, categorias intelectuais preexistentes, as quais apareciam, aliás, como representantes de uma continuidade histórica", não tendo descontinuidades "[...] nem mesmo pela mais complicadas e radicais modificações das formas sociais e políticas". (Ibidem, p. 5).

Para Gramsci (1979), cada grupo social cria para si o seu modelo de intelectual, que o autor designa como intelectual orgânico:

Cada grupo social, nascendo no terreno originário de uma função essencial no mundo da produção econômica, cria para si, ao mesmo tempo, de um modo orgânico, uma ou mais camadas de intelectuais que lhe dão homogeneidade e consciência da própria função, não apenas no campo econômico, mas também no campo social e político [...]. (lbidem, p. 3).

Partindo da afirmação de Gramsci, que cada grupo social "produz os seus intelectuais, cabe destacar os/as intelectuais produzidas pelo grupo social negro. Tal grupo social, compreendido aqui como comunidade negra que busca 
Negros(as) intelectuais:

conhecer, assumir, ajudar a resolver problemas, desafios e dificuldades que essa comunidade enfrenta - preconceitos, discriminações, desigualdades, desrespeito, racismo. Assim, esta investigação é também, como diz Silva (2005, p. 30), "[...] instrumento e forma de luta do povo negro".

Cabe explicitar que "comunidade", segundo Silva (2005, p. 30), é o "meio social e cultural que dá base para o evento científico e a este atribui valor político".

Comunidade que também é científica, e se "[...] constitui em torno de objetivos comuns que ultrapassam a ordem pessoal, se situam e se enraízam em compromisso com construção de uma sociedade justa que garanta iguais direitos e tratamento diverso para diferentes condições, circunstâncias". (SILVA; ARAÚJO-OLIVEIRA, 2004, p. 2).

Comunidade que vem produzindo pesquisas com o objetivo de combater o racismo e todas as formas de discriminações. Mais do que isso, comunidade que tem o objetivo de "[...] formular teoricamente - de forma sistemática e consistente - sua experiência" de séculos de combate à opressão. (NASCIMENTO, 2002, p. 270).

\section{Conclusões: Caminhos a percorrer}

Neste estudo, busca apropriar-se de racionalidades científicas nas quais o "outro da razão" não ocupa apenas os lugares destinados a objetos de pesquisa, mas também, de promotores, colaboradores e executores. Para tanto, inspirou-se "[...] na perspectiva epistemológica, na experiência social do outro lado da linha, isto é, do Sul global não-imperial, concebido como a metáfora do sofrimento humano sistêmico e injusto provocado pelo capitalismo global e pelo colonialismo". (SANTOS, 2010, p. 53).

Inspirar-se pelo Sul significa também sulear, ou seja, "[...] construir paradigmas endógenos, alternativos, abertos, enraizados nas nossas próprias circunstâncias" (ADAMS, 2010, p. 396-397) de povos que vivem no sul do mundo. Paradigmas esses que permitem pensar, refletir a partir das realidades em que vivemos, a partir dos nossos jeitos próprios de ser, de compreender a vida. É fundamental dizer que, a expressão "sulear" não comporta "uma visão dualista e maniqueísta, como se o 'Norte' e 'Sul' fossem apenas uma mera questão geográfica. $O$ 'Sul' está também no 'Norte' e este encontra-se igualmente no primeiro". (Ibidem, p. 386).

Este trabalho também se ancora na "filosofia latino-americana", uma filosofia que "[...] debe descobrir en América Latina su función liberadora, profética; debe anticiparse al pro-yecto de um pueblo,[...] para devolver el pro- 
Negros(as) intelectuais:

yecto iluminado, clarificado, engrandecido, re-creado, cri-ticado" (DUSSEL, 1973, p. 155), sendo que, eu, acrescentaria "enegrecido". Busca-se, assim, enfatiza Dussel (1983, p. 14-15), "[...] uma respuesta decidida y entusiasta a nuestras propuestas. Nuestro pensar encontraba conun proceso popular real, histórico, activo", na presença do outro.

De acordo com Dussel (1995a, p. 116), o outro é "[...] el rostro de alguien que yo [...] 'experimento' como otro; y cuando lo experimento como outro ya no es cosa, no es momento de mi mundo, sino que mi mundo se evapora y me quedo sin mundo ante el rostro del Otro". Continua, o referido autor, que:

[...] cuando me refiera en [...] al "Otro", siempre y exclusivamente me situaré en el nivel antropológico. Es muy simplista pretender refutar la Ética de la Liberación mal interpretando el tema del Otro como un mero problema nofilosófico- teológico [...]. El Otro será el/la otra/o mujer/hombre: un ser humano, un sujeto ético, el rostro como epifanía de la corporalidad viviente humana; será un tema exclusivamente racional filosófico antropológico. Un "absolutamente Otro" en esta ética sería algo así como una tribu amazónica, que no hubiera tenido ningún contacto con la civilización actual, hoy prácticamente inexistente. (Idem, 1998, p. 16).

Isso posto, cabe salientar que o presente texto discutir a importância dos intelectuais negros e negra para a construção de novas epistemologias, e que cada um se educa com o(s) outro(s), numa relação dialógica, em que não deve haver hierarquias, mas sim, uma relação entre o mais e o menos experiente. (SILVA, 2004).

Neste sentido, Dussel (1982, p. 231) pondera que: "[...] na pedagógica, [que não é uma pedagogia], a voz do Outro significa o conteúdo que se revela, e é somente a partir da revelação do Outro que se realiza a ação educativa. $O$ discípulo se revela ao mestre; o mestre se revela ao discípulo". Nessa perspectiva, os processos educativos se dão numa relação de mútua aprendizagem, de troca do mais para o menos experiente e vice-versa: "[...] o processo educativo nega assuntivamente a introjeção do sistema (des-truição) e con-strói afirmativamente a exterioridade pela práxis analítica de libertação, em permanente unidade criativo-inovadora do mestre-discípulo". (DUSSEL, 1982, p. 245).

Isso posto, cabe acrescentar que a educação das relações étnico-raciais é compreendida também como política de reparações, de valorização, de ações afirmativas e de política de reconhecimento, na qual:

reconhecer exige a valorização e respeito às pessoas negras, a sua descendência africana, sua cultura e história. Significa buscar compreender seus valores e lutas, ser sensível ao sofrimento causado por tantas formas de desqualificação: apelidos depreciativos, brincadeiras, piadas de mau gosto 
sugerindo incapacidade, ridicularizando seus traços físicos, a textura de seus cabelos, fazendo pouco das religiões de raiz africana. (BRASIL, 2004, p. 12).

Educar para e nas relações étnico-raciais é buscar romper a concepção de negro presente na sociedade brasileira, romper com os princípios da meritocracia é também descolonizar o poder e o saber.

Educação que é inserida na comunidade, por meios de práticas sociais, suleada por processos educativos, que são percebidos nas relações de aprender-ensinar-aprender. Enfim, educação como processo de luta exercida pela população negra para educar-se e formar cidadãos negros e cidadãs negras que não terão julgada sua humanidade a partir das características físicas, orientação sexual, preceitos religiosos, entre outros.

Educação que é preocupação de intelectuais e particularmente, de negros intelectuais, que buscam por meio de suas ações e produções, construir processos educativos que dialoguem com a sociedade, em especial, com a comunidade negra, objetivando educar para e nas relações étnico-raciais.

Mas do que isto, buscam produzir outras epistemologias, questionando e propondo novos conhecimentos, novas formas de construir os conhecimentos, novas pedagogias, a partir de uma epistemologia desde o Sul, uma outra epistemologia, não hegemônica, que produza outras intelectualidades negras.

\section{REFERÊNCIAS}

ADAMS, Telmo. Sulear. In.: STRECK R., Danilo; REDIN, Euclides; ZITKOSKI, Jaime José. Dicionário Paulo Freire. Belo Horizonte: Autêntica, 2010.

BAUMAN, Zygmunt, Legisladores e intérpretes: sobre modernidade, pósmodernidade e intelectuais. Tradução Renato Aguiar. Rio de Janeiro: Zahar, 2010. Disponível em:

http://search.4shared.com/postDownload/lbTgGVWR/BAUMAN_ZygmuntLegisladores _.html. Acessado em 19/12/2011

BOBBIO, Norberto; MATTEUCCI, Nicola; PASQUINO, Gianfranco. Dicionário de política. Trad. Carmen C., Varriale et al. Brasília: Editora Universidade de Brasília, 1998.

BRASIL. Diretrizes Curriculares Nacionais para a Educação das Relações ÉtnicoRaciais e para o Ensino de História e Cultura Afro-Brasileira e Africana. Brasília, 2004.

CUTI, A empáfia do poeta Gullar. 2011. Disponível

em:https://ceert.org.br/noticias/historia-cultura-arte/1788/o-poeta-cuti-responde-aopoeta-ferreira-gullar-sobre-a-inexistencia-de-uma-literatura-negra. Acessado em 20 abr 2019. 
DUSSEL, Enrique. Para una ética de la liberación latinoamericana. Tombo I, Siglo XXI (ed) Buenos Aires: Editora: Siglio Veintiuno 1973.

Nueva América, 1983

Praxis latinoamericana y filosofía de la liberación. Bogotá:

América, 1995a.

Introducción a La Filosofía de La Liberación. Bogotá: Nueva

Ética de la Liberación en la edad de la Globalización y de la

Exclusión. Madrid: Editorial Trotta, 1998.

A pedagógica latino-americana (a Antropológica II). In: DUSSEL,

Enrique D. Para uma ética da Libertação Latino Americana III: Erótica e

Pedagógica. São Paulo: Loyola; Piracicaba: UNIMEP, p. 153-281, 1982.

Aprender a dizer a sua palavra. In: FREIRE, P. Pedagogia do oprimido. 11. ed. Rio de Janeiro: Paz e Terra, 1970.

FISCHER, Lorenzo. Meritocracia. In: BOBBIO, Norberto; MATTEUCCI, Nicola; PASQUINO, Gianfranco. Dicionário de política. Trad. Carmen C, Varriale et ai. Brasília: Editora Universidade de Brasília, 1998.

GRAMSCI, Antônio. Os intelectuais e a organização da cultura. 4. ed. Rio de Janeiro: Civilização Brasileira, 1979.

GULLAR, Ferreira. Preconceito cultural. In: Folha de São Paulo. Ilustrada. 04.12.2011.

LANDER, Edgardo. La Colonialidad Del Saber: eurocentrismo y ciencias sociales - perspectivas latinoamericanas. Buenos Aires: CLACSO, p. 41-52, 2000.

LIMA, Dora Lúcia. O enfrentamento do racismo em um projeto democrático: a possibilidade jurídica. In: SOUZA, J. (Org.). Multiculturalismo e racismo: o papel da ação afirmativa nos Estados democráticos contemporâneos. Brasília: Ministério da Justiça, p.179-205, 1996.

MAZRUI, Ali A.; ADE AJAYI, J. F.; ADU BOAHEN, A.; TSHIBANGU, Tshishiku. Tendências da filosofia e da ciência na África. In: MAZRUI, Ali A; WONDJI, Christophe (ed). História geral da África, VIII: África desde 1935. Brasília: UNESCO, 2010.

NASCIMENTO, Abdias. O Quilombismo. Brasília/Rio de Janeiro: Fundação Palmares, 2002.

OUTHWAITE, William; BARROMORE, Tom. Dicionário do pensamento social do Século XX. Trad. Eduardo F. Alves e Álvaro Cabral. Rio de Janeiro: Jorge Zahar, 1996. 
QUIJANO, Aníbal. Colonialidad del Poder y Clasificacion Social. In: Special Issue: Festchrift for Immanuel Wallerstein - Part I. Journal of world-systems research. vol.2, summer/fall 2000a, p.342-386. Disponível em: http://biblioteca.clacso.edu.ar/clacso/se/20140506032333/eje1-7.pdf. Acessado em 20/04/2019

Colonialidad del Poder, Eurocentrismo y América Latina. In: E. Lander (org.) La Colonialidad del Saber: Eurocentrismo y ciencias sociales. Buenos Aires: Perspectivas latinoamericanas. CLACSO, p. 201-246, 2000b.

Des/Colonialidad del Poder: El Horizonte Alternativo. In: Observatorio Latinoamericano de Geopolítica. Lima, 2007. Disponível em: http://www.geopolitica.ws/media_files/download/DESCOLONIALIDADDELPODERELH ORIZONTEALTERNATIVO.pdf Acessado em 17/01/2012.

SANTOS, Boaventura de Sousa. Para além do Pensamento Abissal: Das linhas globais a uma ecologia de saberes. In: SANTOS, Boaventura de Sousa; MENESES, Maria Paula. (Orgs.) Epistemologias do Sul. São Paulo: Editora Cortez, 2010.

SANTOS, Joel Rufino. Como podem os intelectuais trabalhar para os pobres. São Paulo Global, 2004.

SARTRE, Jean-Paul. Em defesa dos intelectuais. Trad. Sergio Góes de Paula. São Paulo: Atica, 1994.

SILVA, Helenice Rodrigues da. O intelectual no "campo" cultural francês - do "Caso Dreyfus" aos tempos atuais. In: Varia História, UFMG - Belo Horizonte, v. 21, p. 395413, 2005. Intelectual: Entre mitos e realidades. In: Revista Eletrônica Espaço Acadêmico, Maringá, v. 29, 2003.

SILVA, Petronilha Beatriz Gonçalves e; ARAÚJO-OLIVERA, Sonia Stella. Cidadania, ética e diversidade: desafios para a formação em pesquisa. Apresentado no VI Encuentro - Corredor de las ideas del Cono Sur "Sociedad civil, democracia e integración", Montevideo, 2004.

SOUZA, Daniela Moura Rocha de. Memória de professores intelectuais como interlocutores do republicanismo em Vitória da Conquista entre os anos de $\mathbf{1 9 1 0}$ até 1945. Vitória da Conquista: UESB, 2009.

VIEIRA, Carlos Eduardo. Intelligentsia e intelectuais: sentidos, conceitos e possibilidades para a história intelectual, In: Revista brasileira de educação, no 16, jan./abr, 2008. Disponível em:

http://www.rbhe.sbhe.org.br/index.php/rbhe/article/view/109/120.

Acessado em 21/10/2011

ZUIN, João Carlos Soares. Sobre o neologismo intelectual. In: Estudos de sociologia. Araraquara, v. 8, n. 15, p. 85-101, 2003. 